\title{
Developing a Startup and Innovation Ecosystem in Regional Australia

\author{
Troy Haines
}

\author{
"If a man does not keep pace with his companions, ") \\ perhaps it is because he hears a different \\ drummer. Let him step to the music which he \\ hears, however measured or far away.
}

Henry David Thoreau (1817-1862)

Author, poet, and philosopher

\begin{abstract}
Technology is enabling change at an ever increasing pace, not only in urban contexts, but also in regional centres, where the Internet in particular is enabling entrepreneurs to compete in the global marketplace despite the size and remoteness of their home cities or towns. In regional Australia, the challenges of high unemployment, fading traditional industries, a lack of economic diversity, and a "brain drain" of talent to urban centres highlight the need for novel economic development strategies. Innovation and entrepreneurship are highlighted as potential solutions, but both require knowledge and support to be successful. In this article, the author shares lessons learned as an entrepreneur and through the ongoing development of a self-sustaining startup and innovation ecosystem in the remote region of Cairns, Australia. The model described in this article is now being applied to other regions in Australia, where trained champions are driving the development of startup and innovation ecosystems adapted to regional needs.
\end{abstract}

\section{Introduction}

The Cairns region of Australia (Box 1) faces challenges that are similar to other regional areas in Australia and around the world: declines in traditional industries, a boom-and-bust economic cycle, and a scarcity of "good jobs". With young talent facing a choice between moving to the big cities or staying behind but remaining unemployed, it is no wonder that an air of pessimism can set in. And yet, regional communities are the heart of Australian culture, are often areas of outstanding natural beauty, and can host rich and vibrant communities of individuals that care about each other and their region, and wish to see it flourish. If a region is fortunate enough to have a strong tourism industry, money may flow into the region (at least when the economy is going well); but there still remains a substantial economic development challenge to stimulate sustainable development and long-term prosperity.

In my own experience as an entrepreneur and an "ideas person", I dreamed of creating a company that could change the world, but from my remote location I struggled to figure out how it might be done, even des- pite recent advances in technology and Internet accessibility. Five years ago, I was working on what I thought was going to be "the next big thing" in the personal development industry: iAMconnected (iamconnected.com) a goal-setting and accountability application that connects people to mentors and coaches. But, after investing $\$ 40,000$ of personal savings into the project and having created what I thought was an amazing web application, the platform struggled to gain traction. It was fast becoming apparent that, despite having previously built and sold a successful online travel business, I had no real idea how to build a high-growth venture. As I desperately kept adding features, changing layouts, and changing directions, not much else changed except for my bank balance.

I started looking around my region for help from other entrepreneurs, mentors, key service providers, and investors. But there was no obvious network to tap into, no path to follow, and no regional infrastructure to help build the high-growth, high-scalability startups that promised to be the engines of economic growth. Looking abroad, I could see that places such as Silicon Valley had all the things I needed, but I was not in a position 


\section{Developing a Startup and Innovation Ecosystem in Regional Australia}

Troy Haines

Box 1. An overview of Australia's Cairns region (Cairns Regional Council, 2016)

The Cairns region of Australia is located on the east coast of Far North Queensland, approximately $1,700 \mathrm{~km}$ from Brisbane, which is the nearest urban centre with a population greater than 200,000. Formed in 1876 as a transport and support hub for the local mining and agriculture industries, tourism now plays a major role in the Cairns economy, attracting over 2 million visitors per year. The region is part of the Wet Tropics Rainforest and is commonly known as the "Gateway to the Great Barrier Reef".

Key statistics:

- Land area: $1689 \mathrm{~km} 2$

- Population: 160,000

- Annual population growth in past decade: $2.3 \%$

- Gross Regional Product (GRP): $\$ 7.83$ billion AUD

- Key industries: tourism, agriculture, healthcare, and retail

- Employment growth in past five years: education and training; public administration and safety; healthcare and social assistance (Economy ID, 2015)

- Employment declines in past five years: accommodation and food services; construction; professional, scientific, and technical services (non-computer); retail (Economy ID, 2015)

- Youth unemployment: $22.1 \%$ compared to Queensland average of 14.1\% (Queensland Government, 2015)

- Top markets being addressed by startups: professional services; agriculture; education and training; tourism; information media (Queensland Government, 2016) to relocate. I have family in Cairns and I was committed to the region. So, as a frustrated entrepreneur experiencing the problem first-hand, I sensed that there was an opportunity to build the support structure we needed to assist us and others in the region.

This article shares the lessons learned from the first four years of attempting to develop the Far North Queensland startup and innovation ecosystem, at the heart of which lies theSPACE Cairns (thespacecairns.com), a self-funded, regional startup and innovation hub. In conjunction with stakeholders from across the region, we have developed a model that is showing early signs of success and has been sufficiently encouraging to be ready to roll out to other regional areas across Australia.

Here, I will first describe the gap we needed to fill: what key ingredients were missing from the region that would enable the creation of supporting infrastructure and the required culture of entrepreneurship. Then, I will outline the model we have developed to create a startup and innovation ecosystem in Cairns, but which also serves as a general model to roll out to other regional areas. Finally, I will share specific lessons we have learned. We hope that our experiences will prove valuable to others who are taking a regional approach to stimulating innovation and fostering entrepreneurship.

\section{Key Ingredients}

By studying models developed abroad, such as in Silicon Valley, and through our own experiences and assessments of what regional entrepreneurs need to be successful, we identified the following key ingredients of a startup and innovation ecosystem, which were largely missing, underdeveloped, or disconnected in the Cairns region:

1. Culture: It is essential to develop an entrepreneurial culture within a region, not only among the entrepreneurs themselves but among all stakeholders (Mason \& Brown, 2014; World Economic Forum, 2013). The irony of the regional mindset is that, despite its familiarity with "small businesses", it struggles to understand how a "startup" is something altogether different. For many stakeholders, there is a learning curve in understanding the "scalability" and "innovation" required for a startup to deliver the kind of growth required to fulfill the promise entrepreneurship holds for economic development. Today's regional startups represent a completely new way of doing business, and despite their regional location, 


\section{Developing a Startup and Innovation Ecosystem in Regional Australia}

Troy Haines

they often aim to operate on a global scale from the very beginning. The entrepreneurial culture must reflect this paradigm shift.

2. Champion(s): An ecosystem needs a champion or a team of champions to provide a driving force. A champion is a catalyst that accelerates interest and activity, which is particularly important in the very beginning or when entering a new growth phase. But champions also play important roles in keeping stakeholders focused and moving forward on an ongoing basis. Beyond passion, a champion must inherently understand the necessity for an ecosystem. Ideally, they seek to benefit from the ecosystem as entrepreneurs but also wish to see it developed for the benefit of the broader community. As emphasized by Stam (2015), entrepreneurs with a long-term commitment to a regional ecosystem can play a leadership role because they "are often best positioned to recognize the opportunities and restrictions of the ecosystem, and to deal with them, together with the "feeders" (such as professional service providers and the financial infrastructure)." Here, we see champions as both "leaders" and "feeders" who drive the ecosystem and work with other leading entrepreneurs, key stakeholders, and service providers to ensure its health and sustainability.

3. Network: Working in isolation, an entrepreneur is doomed to fail. A strong and diverse network of other entrepreneurs, mentors, service providers, investors, etc. helps entrepreneurs share ideas, access resources, receive encouragement and advice, overcome barriers, and learn about new opportunities (Isabelle, 2013; Stam, 2015). Although every individual has their own set of relationships, an ecosystem can help formalize, expand, and activate an entrepreneur's network, and act as a support system of mentors, peers, service providers, etc. (Mason \& Brown, 2014; World Economic Forum, 2013).

4. Stakeholder engagement: In a regional context, the saying "it takes a village to raise a startup" is particularly relevant. The ecosystem must ensure ongoing engagement among key stakeholders, meaning those "who have a self-interest in the development of entrepreneurs and the economic development outcomes that result" (Markley et al., 2015). Key stakeholders in a region include local, state, and federal governments; service providers (e.g., accountants, lawyers, and consultants); educational and research institutions; mentors; investors; media; and, most importantly, entrepreneurs.
5. Process: To build capacity in a region, there must be a clear process, or runway, that will lead entrepreneurs from idea to commercialization to exit and provide the necessary support services along the way (Markley et al., 2015). Champions can play a pivotal role in leading entrepreneurs through this process. However, all stakeholders should contribute to process development and execution, and every aspect of the ecosystem should be designed to support and further develop the process.

6. Physical space and events: Entrepreneurs need a place to work and benefit from the availability of coworking space. Having a suitable place to run events and programs also helps to promote engagement among "highly visible and authentic participants" (Stam, 2016) and to stimulate an environment of strategic risk taking and entrepreneurship. Thus, the physical space becomes a means of sharing information and knowledge, building a community, and fostering the necessary culture.

\section{Our Model}

Over the past four years, our company - theSPACE Cairns - has operated as a private equity company, with a mandate of "for profit, for purpose". In the absence of significant funding or a not-for-profit status, our model has required that we "practice what we preach" and generate results (revenue) by delivering real value. This approach has created grass roots growth, which we believe will be sustainable long term. As a result of our efforts to build our own businesses following this model, theSPACE Cairns is now one of several companies owned by our parent company, theSPACE Australasia (Box 2).

In most instances, the startups that we support pay fees for services such as coaching, programs, events, and our membership program. However, when we find something that aligns with our vision and values, then we may become partners in the companies. There is no fixed structure for equity exchange; we negotiate this with individual founders based on their requirements.

theSPACE Cairns team has grown to five members who work with key strategic partners to build a startup and innovation ecosystem in Far North Queensland. The model is designed to fit the needs of our own region, but is also being developed as a replicable and sustainable model that can be "exported" and applied to other regional areas in Australia and beyond. Although no 


\section{Developing a Startup and Innovation Ecosystem in Regional Australia}

Troy Haines

Box 2. Examples of companies owned by the parent company, theSPACE Australasia

- theSPACE Cairns (thespacecairns.com): drives the startup and innovation ecosystem in the Cairns region, including delivering program and events and providing physical space for entrepreneurs

- Emerging Entrepreneurs (emergingentrepreneurs.com.au): a school-based entrepreneurship online learning platform with associated teacher accreditation. It allows teachers to effectively teach students startup skills, collaboration, proactiveness, and responsiveness. Effectively, the platform shows students how to create a job as opposed to look for one.

- Innovation Ecosystems (innovationecosystems.com.au): the organization we use to spread the work we are sharing as part of this article beyond the Cairns region.

- IoT Australasia (iotaustralasia.io): the latest of our companies works with regions and industry to assist them in the establishment of Smart City design.

"one size fits all" approach is possible (or desirable, given the different opportunities possible in each unique region), we have identified fundamental concepts that apply to most regions and can be customized as needed.

Our model recognizes that building a startup and innovation ecosystem in a regional area is fundamentally different than in a large city. The lack of population density if a regional setting means that large investments in hard infrastructure (i.e., hubs, co-working spaces) are often a waste of resources, at least until the ecosystem develops to a critical mass. Time and resources are much better spent educating the community around the startup methodology and how to apply technology to existing industries, with a view to finding high-growth, scalable startup opportunities.

The foundation of our approach is based on coaching and consulting through champions who also drive the ecosystem and the engagement of key stakeholders (Figure 1). This approach developed organically through our efforts in Cairns, where we fulfilled the roles of champions and coaches through our efforts to create our regional startup and innovation ecosystem. Now, we are applying this approach to train local "startup and innovation coaches" to catalyze and drive the development of new ecosystems in other regions of Australia. In a regional setting, this approach has several advantages:

1. It requires little startup capital because it is focused on "soft infrastructure", meaning developing connections throughout the ecosystem and building a culture of entrepreneurship.

2. Champions create an income from the development of the ecosystem, so the approach is self-sustaining. However, the coaching and consulting income should be considered a medium-term supplement that allows them to work on their own high-growth, scalable ideas in the meantime. Ideally, champions are replaced over time as their own startups eventually flourish.

3. The ecosystem is driven by members of the local community.

4. Regions can customize the approach to develop their own brand.

5. Champions are trained in the fundamental principles of entrepreneurship, such as agile planning, establishing core assumptions, building minimum viable products, validating assumptions, and repeating this learning process.

6. When a person's core business comes from within the ecosystem, they are sufficiently motivated to develop that ecosystem. This involves building relationships with key stakeholders, running programs, and offering events.

7. The champion organizes and runs programs and events, and offers consultations and coaching programs. Thus, the approach builds capacity in the region as more and more people develop effective entrepreneurial skills. Mentors still play a substantial and essential role, but the champion teaches a specialized process to guide entrepreneurs through the commercialization runway.

In empowering regions through a champion model, we focus on people who understand the uniqueness of a region and work with them to accentuate opportunities relating to what their region already does well. For example, in the broader community, there is a stigma that startups are all about creating "Uber-type apps" and that related communities are only for "technical geeks". The reality is that the very remoteness of the communities tends to foster an innovative spirit and create diverse opportunities for startups. 


\section{Developing a Startup and Innovation Ecosystem in Regional Australia}

Troy Haines

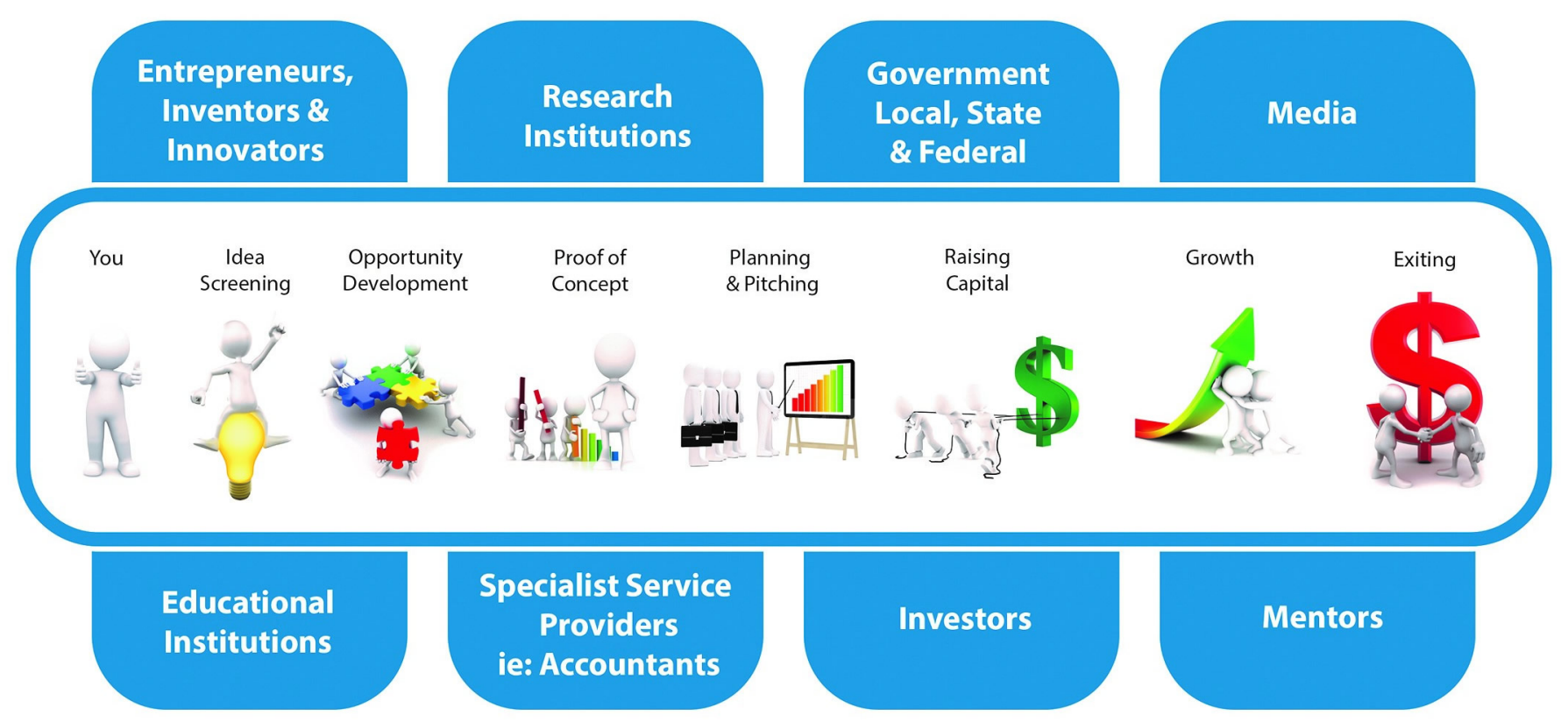

Figure 1. Priority interactions with key stakeholders as startups move through the "runway" to commercialization

Our physical space

We offer physical co-working space to the ecosystem, with desks available on a casual, permanent, or semipermanent basis. In addition to being a convenient and affordable place for entrepreneurs to work, it brings them together to share ideas and facilitate collaboration. As the ecosystem has developed, we have moved to larger facilities to better suit our growing needs for desk space, meeting rooms, private rooms, leisure rooms, kitchen facilities, and communal areas in which to hold events (Figures 2 and 3).

\section{Our programs and events}

Programs and events foster a culture of innovation and help build the foundation of the supporting ecosystem. In Cairns, we offer:

- a ten-week, school-based "Emerging Entrepreneurs" program that teaches high school students about entrepreneurship and links them into the broader ecosystem. We are now rolling out a digital version with supportive teacher accreditation that is presently in numerous schools throughout Queensland

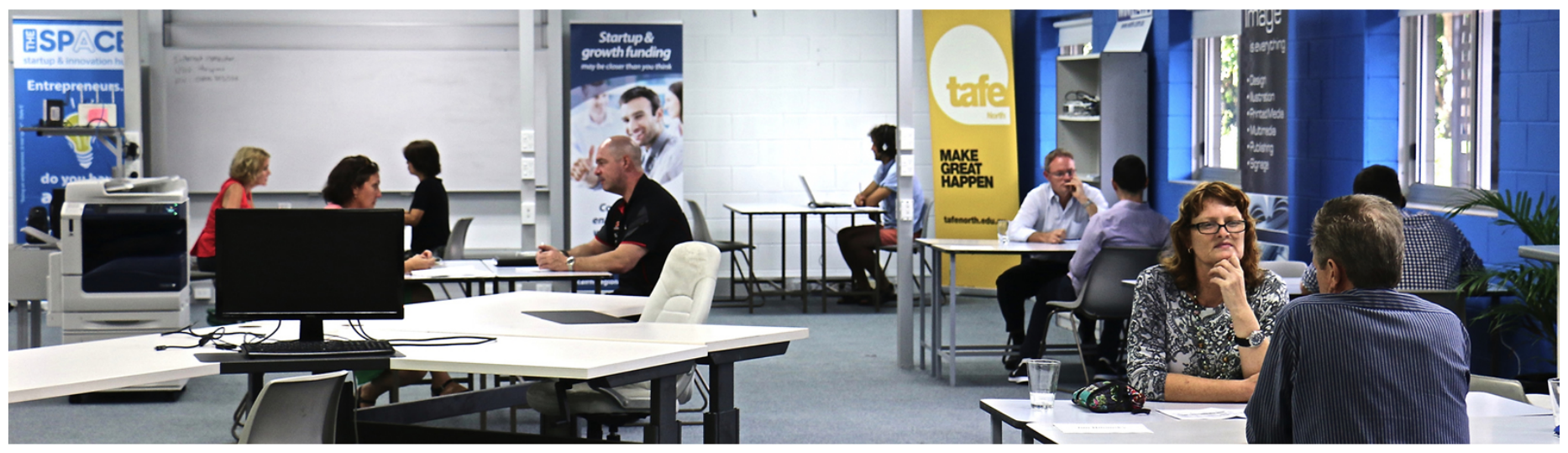

Figure 2. Co-working and event space at theSPACE Cairns 


\section{Developing a Startup and Innovation Ecosystem in Regional Australia}

Troy Haines

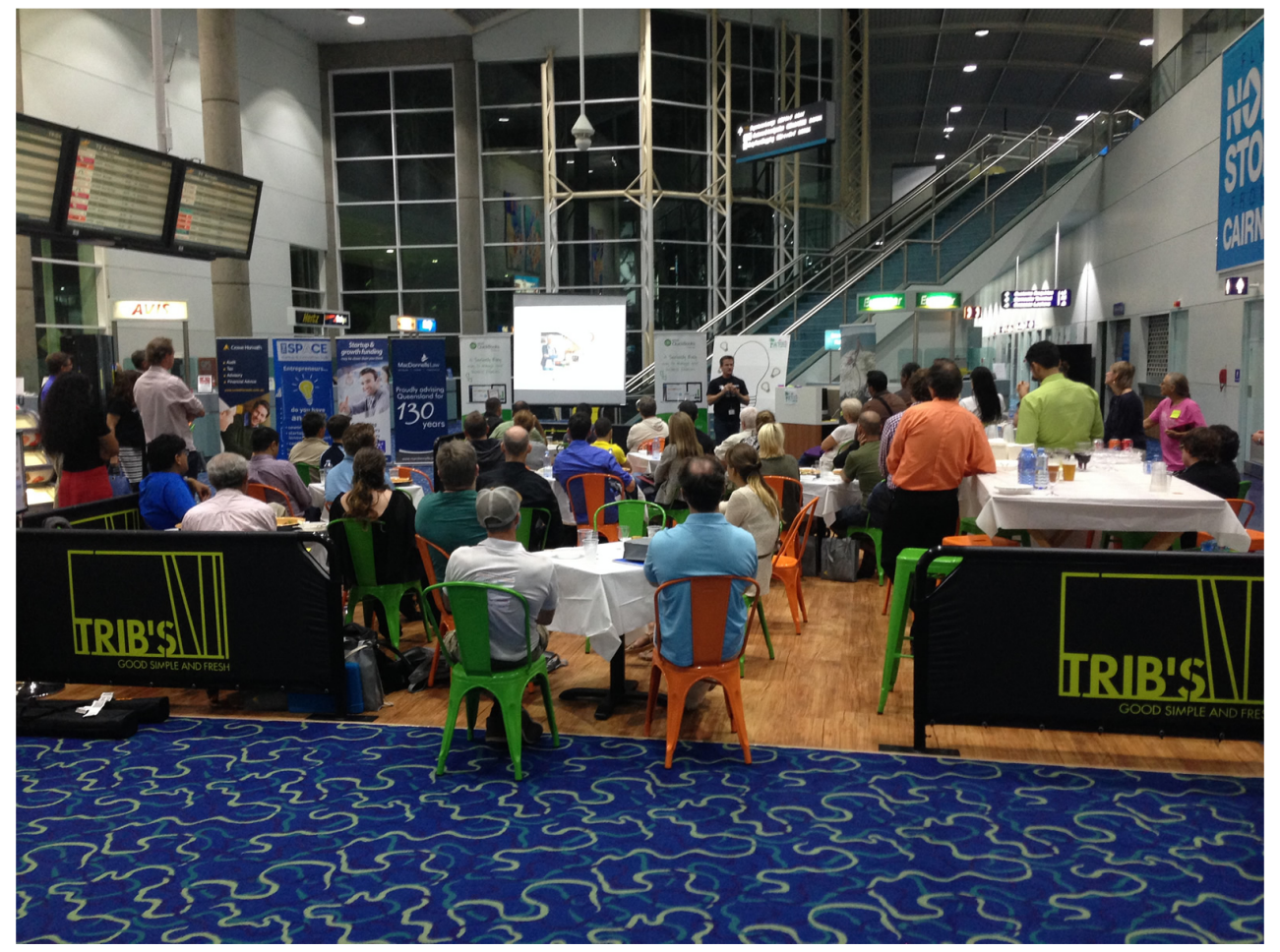

Figure 3. Stakeholders coming together for a pitch event at theSPACE Cairns

- an eight-week "Startup Basecamp" pre-accelerator program that helps budding entrepreneurs validate their ideas

- programs to link startups to small and medium-sized enterprises (SMEs)

- programs to help SMEs, corporations and government agencies to develop their own cultures of innovation and intrapreneurship

- an investment fund (under development) to seed early-stage ideas with the view of then attracting follow-on funding into our region

- a membership program to build the network and engage the community in innovative thinking

- mentoring events that allow entrepreneurs to meet one-on-one with successful startup founders who have exited, founders of growth-stage startups, angel investors, venture capitalists, senior management of technology companies, etc.

- other one-off events and hosting of community activities, such as Startup Weekend Cairns

\section{Early Results}

Four years into the journey, the model that we have developed and applied in Cairns is now being deployed in regions throughout Australia. Measuring progress at this early stage is difficult, but there are a few early signs of success:

- As of June 2016, 592 people, including 137 paid annual members, have attended events or made enquiries through theSPACE.

- theSPACE now has 6 major corporate sponsors and receives support from both local and state governments.

- Up and coming startups that have grown with the support of theSPACE include: Inspection Apps (inspection apps.com) digital checklists, the Natural Evolution (naturalevolutionfoods.com.au) farm and natural food products, the Catch'n'Release (catchnrelease.com.au) anchor retrieval system, and the Emerging Entrepreneurs (emergingentrepreneurs.com.au) school-based entrepreneurship education program.

- A recently completed study conducted by the Queensland Government, which mapped startup ecosystems 


\section{Developing a Startup and Innovation Ecosystem in Regional Australia}

Troy Haines

throughout Queensland, showed that Cairns has the highest density of startups per capita of any region in Queensland (Queensland Government, 2016). Cairns has one startup for every 5,300 people compared with, for example, South East Queensland, which has one startup for every 12,700 people. However, the study also highlighted that the money raised by these startups in Cairns remains relatively low.

- In 2014, my fellow theSPACE Co-Founder, Damian Zammit, and I were named Innovation Champions by the Minister of Innovation and the Premier of Queensland. We were further inducted into the Queensland Government Innovation Wall of Fame for the work we have done thus far in building the North Queensland startup and innovation ecosystem.

- Through its coaching program, theSPACE helped an established aluminum fabrication company survive the collapse of the Cairns construction industry in the wake of the global financial crisis. Norweld's (norweld .com.au) directors were encouraged to closely examine their business to identify what it did particularly well, what it could uniquely offer, and how they could scale and grow it beyond the Cairns region. By refocusing the business on fabricating premium, heavy-duty aluminum trays and canopies for utility vehicles, or "utes", the company was able to reinvent itself. Defying the trend of a shrinking manufacturing sector, in the last 2 years Norweld has gone from 18 to 35 staff and has taken over a large manufacturing plant. Today, Norweld ships its products throughout Australia and is pursuing international sales.

- In 2015, theSPACE won a national challenge through Sustainable Economic Growth for Regional Australia (SEGRA; segra.com.au), and we are now working with them to support regions throughout Australia to develop their own startup and innovation ecosystems, as described in the next section.

- In 2016, Australian Prime Minister Malcolm Turnbull visited theSPACE (Figure 4) to see first-hand the innovations created by our regional entrepreneurs and to announce $\$ 10$ million in funding for an Innovation Centre to be built at James Cook University in Cairns, which theSPACE will collaborate with as a commercialization partner (Groom, 2016). This federal government funding is in addition to $\$ 10$ million in funding from the state government and a further $\$ 30$ million from private investors, resulting in a total investment

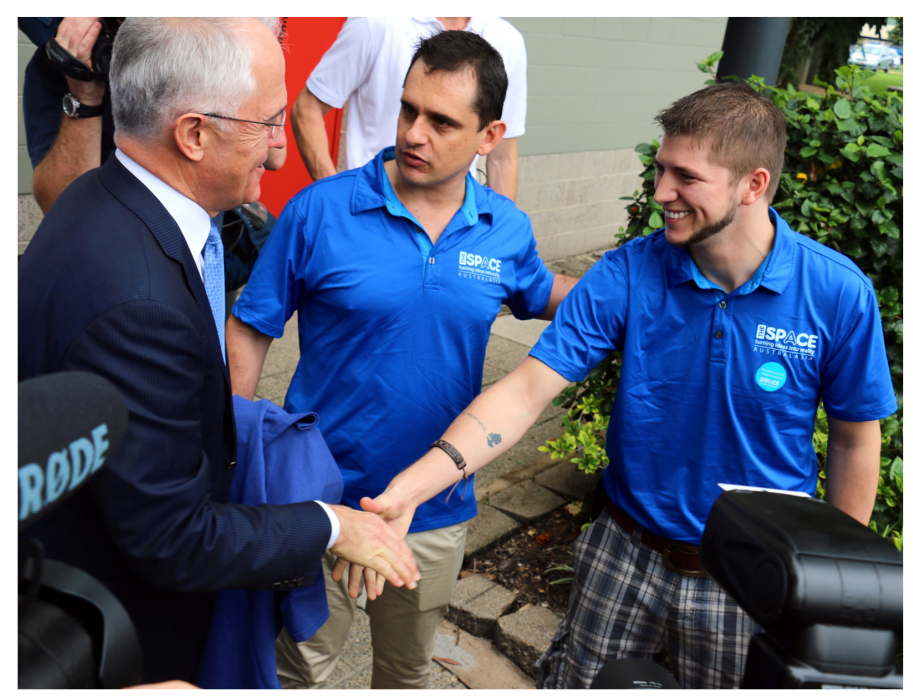

Figure 4. Australian Prime Minister Malcolm Turnbull meets members of theSPACE Cairns team

of $\$ 50$ million for the Cairns Innovation Centre. A video of the Prime Minister's visit to theSPACE and his funding announcement, which provides context for the investment in alignment with the National Innovation and Science Agenda (Australian Government, 2015), is available here: youtu.be/nqOWBlVpUcs

\section{Next Steps: Applying the Model to Other Regions}

Moving forward, with the support of SEGRA, we are beginning to evaluate the status of other regions with the aim of applying the model we have started in Cairns to the development of startup and innovation ecosystems across regional Australia. This work is being supported by Charles Sturt University (csu.edu.au) as an academic research partner to: i) review current literature on regional startup/innovation ecosystems, ii) research different models that are currently being utilized in regions, and iii) compare the findings to the results generated by the champion model in Cairns.

Early-stage discussions have taken place with 13 regions, which have highlighted challenges such as funding the initial training and overcoming general parochialism of regions, which we are presently working to overcome. Also, we recently started working with a pilot region - the Atherton Tablelands, a rural area $80 \mathrm{~km}$ from Cairns - to assist them in the development of their own startup and innovation ecosystem. An early snapshot of this pilot region has revealed the following: 


\section{Developing a Startup and Innovation Ecosystem in Regional Australia}

Troy Haines

1. The region has a few passionate drivers for the ecosystem, but no real champions.

2. Key stakeholders can be identified, but very few have been effectively engaged.

3. The region lacks a physical space to serve as the hub for an ecosystem.

4. A limited number of events have been held, including eight small events relating to innovation and entrepreneurship in addition to one startup weekend.

Accordingly, our work in this pilot region is focused on:

1. Appointing a Champion Team of nine people who are currently being mentored by theSPACE.

2. Supporting the region as national host for the international Future Agro Innovation Challenge (futureagro challenge.com). Agriculture is a primary industry in the Atherton Tablelands region, and is therefore an area of focus for the ecosystem.

3. Building the ecosystem while also building the region's own consultancies and startups.

4. Hosting twice-monthly startup and innovation events run by the region's champions.

\section{Lessons Learned}

Although our model is now well developed and tested locally and is being deployed in other regions, our early ecosystem-building efforts involved a lot of trial and error, through which we learned many lessons. Some key lessons in the form of recommendations for others wishing to build a regional startup and innovation ecosystem are outlined below:

\section{Recognize that building an ecosystem takes more than} just funding an accelerator or incubator: Ecosystem building requires bringing together diverse components - especially people - and developing a process to turn ideas into reality. The goal is to bring long-term capability and sustainability to the region, from which companies will emerge, not just in the short term, but long into the future.

2. Take a lean approach to space: A physical space provides a place to run events and programs and gives entrepreneurs a place to work, and it helps provide a focus to the ecosystem. However, many ecosystems put too much effort (and expense) into providing a polished physical space right from the beginning. We have found that, in the early stages of building an ecosystem, growing the community and soft infrastructure (i.e., the ecosystem and culture) are far more important. We encourage a lean mentality to growing the co-working space in step with the needs of the growing community.

3. Reflect the region: Although the approach can generally be applied to any region and it encourages entrepreneurs to start global businesses, it is important for the ecosystem to reflect and embrace the uniqueness of its own region.

4. View technology as only part of the solution: A startup and innovation ecosystem is not just about developers "building apps". For example, in our experience, some of the most innovative people in the regions are trades people. The opportunity is to bring technology to what regions already do well and educate our entrepreneurs on an effective commercialization process.

5. Remunerate ecosystem builders: We observed that ecosystems that rely solely on volunteers put tremendous strain on these people and inevitably, despite their best efforts, they burn out and move on. Having a trained startup and innovation coach helps to overcome volunteer burnout.

6. Focus on sustainability: Initial funding from high net worth individuals or government agencies to start an ecosystem certainly can be helpful, but the benefits will soon dry up if the underlying business model is not sustainable or if the initial investment only provides hard infrastructure. Building a community is far more important.

7. Pay attention to roles: In an ecosystem, stakeholders may make or take particular roles that might do more harm than good, even when their intentions were good. This risk highlights the need to build and maintain relationships with key stakeholders, encourage connections, and help individuals or organizations find or create beneficial roles.

8. Build from the grassroots up: Having a trained startup and innovation coach provides early-stage support for entrepreneurs that are often too early stage for most mentors to spend significant amounts of time nurturing. This approach fosters a grassroots approach to ideation in the communities and helps build the ecosystem organically. 


\section{Developing a Startup and Innovation Ecosystem in Regional Australia}

Troy Haines

\section{Conclusion}

Although it is still early days, we are seeing positive activity in regions and champions inspired to do the work in building the ecosystems. Our regions are beginning to understand that building ecosystems for economic growth is far more than a short-term goal of establishing an incubator or accelerator. Building an ecosystem is about creating a cultural shift that will allow a community to be strategically agile long into the future. It requires working with students in schools and universities and teaching them the fundamentals of entrepreneurship, particularly how to turn an idea into a scalable business. The champion's role is to engage with stakeholders and founders to shift their attention globally and give them the knowledge and support they need to turn their dreams into reality.

A region's economic development depends on a widespread culture of entrepreneurship that is not risk averse and views strategic failure as a learning opportunity. To remain relevant in the modern global economy, regions in Australia (and around the world) must build the ecosystems and apply the processes that help entrepreneurs turn good ideas into high-growth, scalable businesses. That is the path we have started taking in Cairns, and we hope our model and experiences will encourage other regions to do the same.

\section{About the Author}

Troy Haines is Co-Founder and CEO of theSPACE Australasia in Cairns, Australia. He is also a Startup and Innovation Coach who has worked with hundreds of entrepreneurs across Australia to help them commercialize their ideas. Amongst many awards, he was named Innovation Champion in 2014 by the Minister of Innovation and Premier of Queensland. He was also inducted into the Queensland Government Innovation Wall of Fame for his work in building the North Queensland startup and innovation ecosystem. Troy and the team at theSPACE have developed startup and innovation programs, which they deliver across a wide audience, from high school students and SMEs to government (and everyone in between). He holds a Bachelor's degree in Business (Marketing) from Australia's Charles Sturt University and is currently working towards a Master's degree in Applied Innovation and Entrepreneurship from the University of Adelaide.

\section{References}

Australian Government. 2015. National Innovation and Science Agenda. Canberra: Commonwealth of Australia, Department of the Prime Minister and Cabinet.

http://www.innovation.gov.au/page/agenda

Cairns Regional Council. 2016. About Cairns. Cairns Regional Council. Accessed June 1, 2016:

http://www.cairns.qld.gov.au/region

Groom, N. 2016. Trying to See the Future, Malcolm? PM Turnbull Dons Virtual Reality Headgear as He Tours a Science and Innovation Centre on the Election Trail. Daily Mail Australia, June 22, 2016. Accessed June 22, 2016:

http://www.dailymail.co.uk/news/article-3653887/Malcolm-

Turnbull-dons-virtual-reality-headgear-innovation-centre-

Cairns.html

Queensland Government. 2015. Regional Youth Unemployment-July 2015. Brisbane, Australia: Queensland Government Statistician's Offices.

http://www.qgso.qld.gov.au/products/reports/reg-youthunemployment/reg-youth-unemployment-201507.pdf

Economy ID. 2015. Employment (Total) by Industry. Accessed June 10, 2016:

http://economy.id.com.au/cairns/employment-by-industry

Isabelle, D. A. 2013. Key Factors Affecting a Technology Entrepreneur's Choice of Incubator or Accelerator. Technology Innovation Management Review, 3(2): 16-22.

http://timreview.ca/article/656

Mason, C., \& Brown, R. 2014. Entrepreneurial Ecosystems and Growth Oriented Entrepreneurship. The Hague, Netherlands: OECD \& LEED.

http://www.oecd.org/cfe/leed/Entrepreneurial-ecosystems.pdf

Markley, D. M., Lyons, T. S., \& Macke, D. W. 2015. Creating Entrepreneurial Communities: Building Community Capacity for Ecosystem Development. Community Development, 46(5): 580-598.

http://dx.doi.org/10.1080/15575330.2015.1041539

Stam, E. 2015. Entrepreneurial Ecosystems and Regional Policy: A Sympathetic Critique. European Planning Studies, 23(9): 1759-1769.

http://dx.doi.org/10.1080/09654313.2015.1061484

Queensland Government. 2016. Regional Queensland Startup Ecosystem Report. Brisbane, Australia: Queensland Government. http://www.qld.gov.au/dsiti/assets/documents/regional-qldstartup-ecosystem-report.pdf

World Economic Forum. 2013. Entrepreneurial Ecosystems around the Globe and Company Growth Dynamics. Davos: World Economic Forum.

Citation: Haines, T. 2016. Developing a Startup and Innovation Ecosystem in Regional Australia. Technology (cc) BY Innovation Management Review, 6(6): 24-32. http://timreview.ca/article/994

Keywords: entrepreneurship, startups, innovation, ecosystems, incubation, mentorship, regional, theSPACE, Cairns, Australia 